\title{
TRANSTEXTUALIDADES NA NARRATIVA DA TELEVISÃO BRASILEIRA: transformações textuais num esquete humorístico de Os Trapalhões
}

\author{
Rafael Jose Bona ${ }^{1}$
}

Resumo: O artigo tem como objetivo analisar as transformações textuais de um esquete de humor televisivo brasileiro intitulado $O$ grotóco do caqui (1988), da comédia de situação (sitcom) Os Trapalhões e exibido na TV Globo. O esquete faz uma transformação textual da parte final do clássico Branca de Neve (Irmãos Grimm). Se faz uma análise por meio da quinta categoria da transtextualidade, a hipertextualidade, proposta por Genette (2010). Os resultados constatam que há uma circulação de textos dos mais diversos, e não somente de Branca de Neve. Há uma reciclagem de diferentes obras num constante contato de entrelaçamento intertextual. Este cenário se configura como uma espécie de jogo hipertextual em que se remetem às diferentes formas de produções textuais, na utilização de hipotextos, ao jogar com eles e, ao mesmo tempo, se jogar dentro deles.

Palavras-chave: Transtextualidade; comunicação; televisão; humor; Os Trapalhões.

Abstract: The article attempts to analyze the textual transformations of a Brazilian television humor sketch entitled O grotóco do caqui (1988), from the sitcom Os Trapalhões, broadcast by TV Globo. The sketch makes a textual transformation of the final part of the classic Snow White (Brothers Grimm). An analysis is made through the fifth category of transtextuality, the hypertextuality proposed by Genette (2010). The results show that there is a circulation of the most diverse texts, and not only Snow White. There is a recycling of different work in a constant contact of intertextual relation. This scenario is configured as a kind of hipertextual game which makes reference to the different forms of textual productions, through the use of hypotexts, as it plays with them and, at the same time, it plunges into them.

Keywords: Transtextuality; communication; TV; humor; Os Trapalhões.

\section{Introdução}

No mundo há uma infinidade de tipos de narrativas e essas podem ser sustentadas de acordo com a linguagem, gênero, imagem, pela mistura de substâncias presentes nas lendas, nas fábulas, nos mitos, entre outras. Ela está presente em todos os tempos e lugares, em todas as sociedades e nasceu junto com a civilização humana (BARTHES, 1976).

Nesse contexto narrativo, Os Trapalhões, antigo grupo humorístico da televisão brasileira, formado por Didi, Dedé, Mussum e Zacarias, possuía elementos e situações oriundos da cultura e da sociedade brasileira que eram sustentados numa estrutura narrativa de curta duração, em formato de esquetes de humor, e eram trabalhados diversos estereótipos nacionais, muitas paródias dos mais diferentes contextos, e provocam um humor simples e com uma certa carga de double coding. Para Eco (2011), o double coding possibilita dupla leitura de um texto em que o leitor está avisado de forma intertextual e "saboreia" a ironia

${ }^{1}$ Doutor em Comunicação e Linguagens pela Universidade Tuiuti do Paraná (UTP). Docente da Universidade Regional de Blumenau (FURB) e da Universidade do Vale do Itajaí (UNIVALI). 
daquele momento da obra. E isso vale para o contexto quando a citação está deslocada da fonte. Conforme Eco (2011, p. 214), "não apenas a piscadela culta que lhe dirige o autor, mas também os efeitos de enfraquecimento ou mutação de significado".

A estrutura narrativa do grupo na televisão era, sucessivamente, um enredo que envolvia os quatro personagens, no qual Didi era sempre o personagem principal e levava vantagem em relação aos demais. Os esquetes sempre provocavam o riso com representações das situações simples do cotidiano e, ao mesmo tempo, com um texto carregado de elementos oriundos de narrativas externas ao grupo. Seja um poema, uma epopeia, uma peça teatral, uma obra de arte, todos eles derivam de uma imitação, algo vastamente pontuado por Aristóteles na Poética. Portanto, nesse contexto, toda narrativa é imitação de algo e possui sua estrutura distinta com começo, meio e fim. Segundo Aristóteles (1993, p. 27), “o imitar é congênito no homem (e nisso difere dos outros viventes, pois, de todos, é ele o mais imitador, e, por imitação, aprende as primeiras noções), e os homens se comprazem no imitado".

Os programas/esquetes televisivos de Os Trapalhões são como hipertextos que derivam de obras já existentes que partem da premissa exposta por Comparato (2009): toda comédia de situação é hipertextual, geralmente possui uma estrutura curta e que provoca o riso por meio de situações cômicas dos personagens e por diálogos.

O termo hipertexto ou palimpsesto é teorizado por Genette (2010). O autor faz uma alusão a um pergaminho em que é possível ler vários textos, antigos sobre os novos, propriamente sem escondê-los. Nesse sentido, todas as obras são derivativas de outras, sejam por transformações ou imitações. Um texto sempre poderá ser lido por outro texto consequentemente.

Genette retoma vários de seus conceitos trabalhados em suas obras relacionadas à literatura e à poética. A partir dos discursos, enunciação, gêneros literários, ele entende os textos como uma forma de transtextualidade, em que se coloca a relação textual com outros textos. O autor esboça cinco formas em que os textos podem se relacionar: (1) por meio da intertextualidade; (2) da paratextualidade; (3) da metatextualidade; (4) da arquitextualidade; e da (5) hipertextualidade. Todas essas relações textuais são pertinentes a uma ordem de abstração, implicação e globalidade do texto. Entretanto, o autor esclarece que "não devemos considerar os cinco tipos de transtextualidade como classes estanques, sem comunicação ou interseções. Suas relações, são, ao contrário, numerosas e frequentemente decisivas" (GENETTE, 2010, p. 22). 
Ao entender que as práticas intertextuais não ocorrem apenas em textos, mas em qualquer produção cultural, Stam (2003) adapta os conceitos de Genette para a linguagem audiovisual cinematográfica. Estes podem, também, ser direcionados aos textos televisivos.

O objetivo deste artigo, portanto, é analisar um esquete de Os Trapalhões, veiculado na TV Globo, em 1988, intitulado $O$ grotóco do caqui. O esquete é analisado a partir da teoria de Genette (2010) sobre a quinta categoria da transtextualidade, a hipertextualidade.

\section{A hipertextualidade e Os Trapalhões}

O termo hipertextualidade é vastamente utilizado e estudado nas áreas da Computação e da Comunicação Social e remete, quase sempre, à questão do hipertexto digital. Entretanto, quando Genette concebeu o termo hipertextualidade, no início dos anos de 1980, era uma época em que não existia a cultura digital oriunda da internet. O termo hipertexto também se reporta aos anos de 1950 e os de 1960, em que se tentava criar um hipertexto por meio do computador, independente da internet, com intuito de ligar um texto a outro ${ }^{2}$.

Nesse sentido, portanto, os produtos televisivos de Os Trapalhões são analisados a partir da ótica de Genette, sobre a intertextualidade/hipertexto. Assim, não se leva em conta, o hipertexto digital propiciado pela rede mundial de computadores, haja vista que $O s$ Trapalhões fizeram sucesso no Brasil muito antes da internet e na mesma época em que Genette escreveu a obra Palimpsestos.

Genette define a hipertextualidade como "toda relação que une um texto B (que chamarei hipertexto) a um texto anterior A (que, naturalmente, chamarei hipotexto) do qual ele brota de uma forma que não é a do comentário" (GENETTE, 2010, p. 18). Para o autor, portanto, todo hipertexto deriva de outro anterior e isso ocorre de duas formas: pela transformação simples ou direta, ou pela transformação indireta ou imitação.

A transformação simples ocorre no processo em que o hipertexto (texto B) não precisa citar o hipotexto (texto A), mas o hipertexto não existiria sem o hipotexto. Ao levar esse contexto para os hipertextos televisivos de Os Trapalhões, constata-se que esse processo é corriqueiro, pois se faz a transposição de diversas obras que são transformadas por meio de paródias, travestimentos e imitações (pastiche ou apócrifo).

\footnotetext{
${ }^{2} \mathrm{O}$ objetivo do artigo não é adentrar em conceitos sobre hipertexto, mas esclarecer que o termo hipertexto,
} utilizado para a análise do produto televisivo, é o de Genette (2010). 
A paródia é entendida por Genette (2010), como um desvio textual por sua transformação simplificada; já o travestimento é uma transformação de estilo com função degradante. A imitação pode ocorrer por meio da prática do pastiche. Toda imitação é também uma transformação,

mas de um procedimento mais complexo, pois - para dizê-lo aqui de maneira ainda muito resumida - exige a constituição prévia de um modelo de competência genérico (que chamaremos épico) [...] e capaz de gerar um número indefinido de performances miméticas. Esse modelo constitui, então, entre o texto imitado e o texto imitativo, uma etapa e uma mediação indispensável, que não encontramos na transformação simples ou direta. Para transformar um texto, pode ser suficiente um gesto simples e mecânico [...]; para imitá-lo, é preciso necessariamente adquirir sobre ele um domínio pelo menos parcial: o domínio daqueles traços que se escolheu imitar [...] (id., p. 19).

A hipertextualidade, portanto, é uma classe de textos e existe por meio do trânsito textual e com diferentes aspectos. Segundo o referido teórico (id., p. 43), "isso não exclui absolutamente a possibilidade de práticas mistas, mas é que um mesmo hipertexto pode ao mesmo tempo, por exemplo, transformar um hipotexto e imitar um outro".

\section{Metodologia e procedimentos}

Esta pesquisa se classifica como documental e sua abordagem qualitativa. Os procedimentos metodológicos iniciaram com uma observação flutuante de mais de seis horas dos programas de televisão produzidos entre os anos de 1977 e de 1993, a partir do DVD oficial do grupo (produção da Globo Marcas, 2008). Também foram assistidos vídeos obtidos por busca online no site YouTube ${ }^{3}$. Refere-se a material televisivo, especificamente, produzido no mesmo período e postado por fãs.

A partir dessas observações, fez-se a seleção do mais representativo para a quinta categoria, a hipertextualidade. A amostragem ocorreu de forma não probabilística por julgamento. A escolha do esquete se deu de forma intencional, ao verificar que este possuía vários tipos de transtextualidade e apareciam de forma heterogênea. Conforme Genette (2010, p. 5), "um texto pode sempre ler um outro, e assim por diante, até o fim dos textos. Dessa forma, a seleção considerou apenas a categoria da hipertextualidade.

\footnotetext{
${ }^{3}$ Disponível em www.youtube.com.br, acessos intermediários entre os meses de dez. 2015 a ago. 2016. Busca pelas palavras-chave: Trapalhões; Didi; Dedé; Mussum; Zacarias.
} 
Machado e Vélez (2007) descrevem algumas dificuldades de se estudar um material televisivo, pois toda análise, desse segmento, é complexa devido à diversidade de linguagens hipertextuais que são abordadas nesses materiais. Um problema particular nesse contexto é que há uma diferença entre o texto verbal e o produto televisivo. Sobre citar a televisão, os autores dizem que "não há como incluir na análise, a título de citação, os trechos audiovisuais de que se está falando" (id., p. 12). Por vezes, é necessário recorrer a fragmentos dos roteiros, fotografias (still frames), partituras musicais, entre outros, com o objetivo de compreender melhor a análise televisiva. As análises literárias, por sua vez, têm vantagem em relação à televisão, pois trabalham com signos da mesma natureza. Os autores complementam que:

para citar um trecho da obra literária analisada basta abrir aspas e reproduzir o texto. Evidentemente, na análise de televisão não é possível abrir aspas para inserir o fragmento de programa que se está discutindo. A análise do programa de televisão tem a desvantagem, portanto, de não poder contar com o próprio discurso sobre o qual fala. (MACHADO; VÉLEZ, 2007, p. 12).

Por essa razão, alguns still frames dos esquetes foram recortados e inseridos no corpo do texto, para possibilitar melhor leitura em relação ao hipertexto televisivo de Os Trapalhões que é descrito a partir da sua narrativa e analisado sob a teoria transtextual de Genette.

\section{A transformação textual de Branca de neve}

A hipertextualidade, no seu sentido de relação textual, contribui na evocação das obras originais e suas derivações. Para Stam (2003, p. 233), nos hipertextos há uma transformação por meio de "seleção, amplificação, concretização e atualização". Com o objetivo de identificar o esquema de transformações textuais mais representativas de Os Trapalhões, é aqui analisado o esquete hipertexto $O$ grotóco do caqui (1988) que evoca a parte final do clássico infantil, o hipotexto Branca de Neve (Irmãos Grimm). Esta obra já teve diversas adaptações e uma das mais famosas é a versão de Walt Disney para os desenhos animados, de 1937, com o título de A Branca de Neve e os sete anões (ver figura 1).

Branca de Neve é um conto que tem sido transmitido oralmente desde a Idade Média, na Alemanha. Entre as primeiras décadas do século XIX, os irmãos Jacob e Wilhelm Grimm publicaram o conto intitulado Branca de Neve, juntamente com outros, na obra Kinder-und Hausmaërchen. A transformação de Os Trapalhões se concentra na parte final da obra - 
quando a personagem Bruxa oferece a maçã envenenada para Branca de Neve - numa espécie de excisão textual, em que ocorrem práticas mistas de hipertextualidades.

Genette (2010) constata que, em muitos hipertextos, é comum a prática da excisão, no sentido de melhorar a obra e com a intenção de suprir partes inúteis. $\mathrm{O}$ autor exemplifica com as muitas edições, destinadas ao público infantil, da obra Robinson Crusoé (1719, Daniel Defoe). Nestas há sempre uma supressão de fatos e se dá ênfase apenas ao naufrágio do navio e a vida do personagem na ilha.

O diálogo que o esquete faz com a obra de origem evidencia uma hipertextualidade com o seu hipotexto, no qual são transpostos não apenas uma parte da narrativa do conto de fábulas mas, também, uma transformação de forma parodiada e travestida, com o intuito de provocar o riso. Conforme Genette (2010, p. 50) “a fábula é um dos alvos preferidos do travestimento popular (oral), e por duas razões bem evidentes, que são sua brevidade e sua notoriedade".

O título do esquete não evoca arquitextualmente Branca de Neve, mas todo o quadro é uma parte transposta da história, de forma parodiada. A paródia, no seu sentido etimológico, deriva de “ôdè, que é o canto; para, 'ao longo de', 'ao lado'; parôdein, daí parôdia, que seria (portanto?) o fato de cantar ao lado, de cantar fora do tom, ou numa outra voz, em contracanto [...], ou ainda, cantar num outro tom: deformar, portanto, ou transpor uma melodia" (GENETTE, 2010, p. 26).

Para Samoyault (2008), a paródia é uma prática de transformação de uma obra, na qual se faz caricatura, reutilização, transposição e se exibe sempre um liame, relacionado com a literatura existente. A paródia é facilmente reconhecida pelos leitores/espectadores, pois há sempre algo visível no texto que indica seu uso.

O esquete inicia com Mussum (tra)vestido de Branca de Neve. Ele dança ao som da clássica música da obra de Walt Disney: “Eu vou, eu vou, pra casa agora eu vou...”. A música é inserida no texto como uma transtextualidade/imitação (já traduzida para o português). $\mathrm{O}$ personagem Mussum, afrodescendente, travestido de uma personagem feminina e que remete à imagem de Branca de Neve, convoca uma inversão de valores, algo que se relaciona ao conceito de carnavalização, muito presente em obras de comédia. Bakhtin (2010, p. 360) esclarece que as práticas carnavalescas "oferecem tantas coisas ao avesso, rostos invertidos, proporções violadas de propósito. Isto se manifesta sobretudo nas vestimentas das pessoas: homens fantasiados de mulheres e vice-versa, roupas vestidas do avesso, roupas do alto postas 
no lugar das de baixo". O carnaval inverte a ordem dos valores, instala a comédia e a zombaria, é uma cultura simbólica do oprimido e está intrinsicamente relacionado às práticas paródicas (ver figura 2).

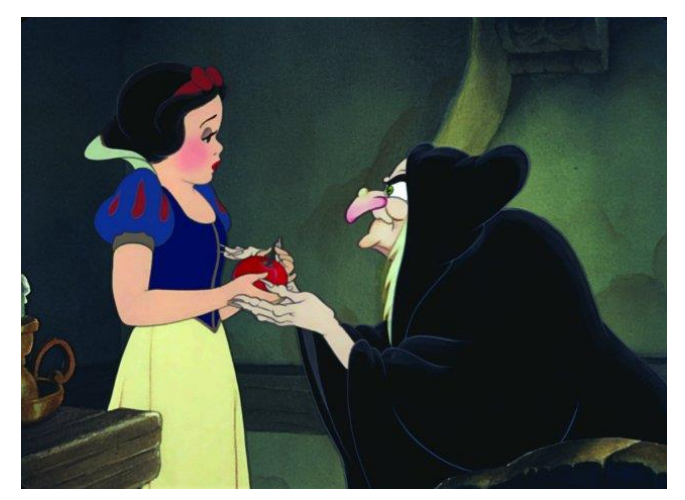

Figura 1: still frame do filme A branca de neve e os sete anões (1937).

Fonte: recorte do autor.

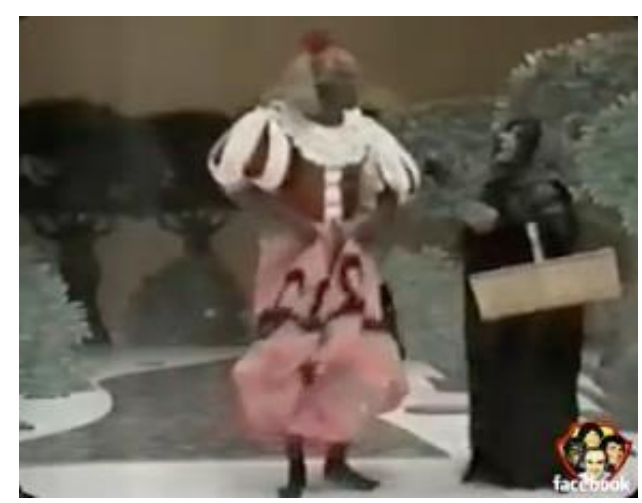

Figura 2: still frame do esquete $O$ grotóco do caqui (1988).

Fonte: recorte do autor.

Em seguida aparece uma personagem vestida de bruxa e pergunta para Mussum: "Olá, linda menina, queres provar uns dos meus caquis?", e ele responde: "Mas o negócio da frescura da história não era a maçã, dona?". A bruxa pergunta: "Tu sabes quanto é que está custando o quilo da maçã?" (ver figura 3). Neste trecho é percebida novamente a zombaria, um dos artifícios para a provocação do riso. A bruxa insiste para que Mussum prove o caqui e ele pergunta: "É caqui de quê? Caipirinha de quê?". A citação de bebida alcóolica no discurso do personagem Mussum faz autorreferência à linguagem do seu próprio personagem, conhecido de outros esquetes. Conforme Samoyault (2008, p. 99) “a linguagem dos personagens, como do narrador, se constitui assumindo o peso dos enunciados anteriores". 


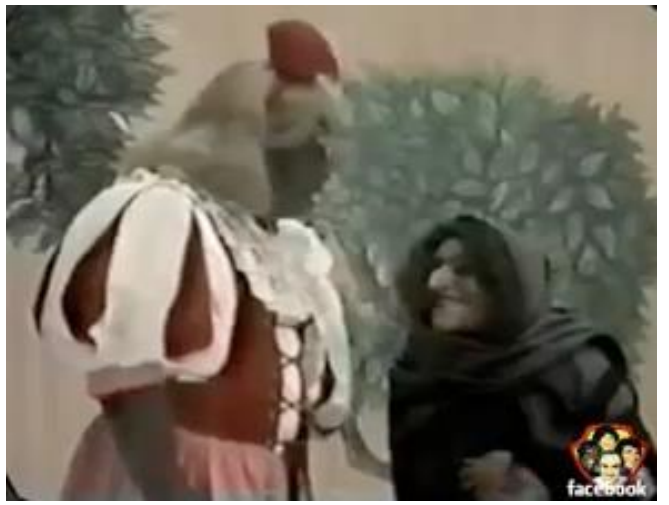

Figura 3: still frame do esquete $O$ grotóco do caqui (1988).

Fonte: recorte do autor.

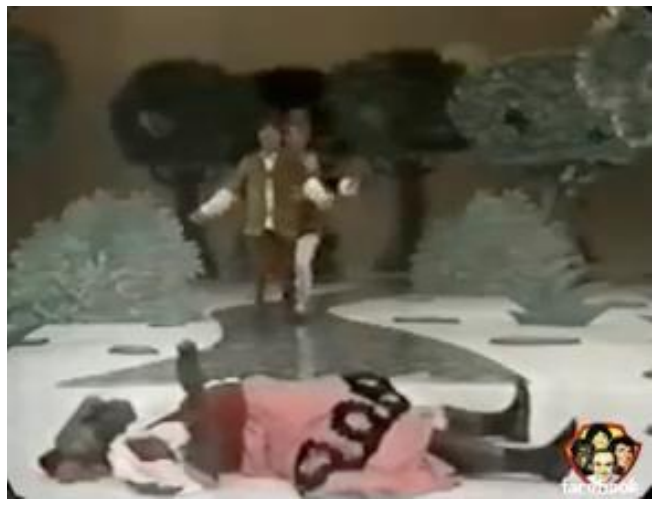

Figura 4: still frame do esquete $O$ grotóco do caqui (1988).

Fonte: recorte do autor.

Mussum prova o caqui e cai ao chão, logo aparecem Didi e Zacarias trajados de príncipes medievais (uma alusão) e se espantam com o corpo caído (ver figura 4). "Saravá meu irmão", fala Didi. "O que é isso?", fala Zacarias, e Didi responde "isso é trabalho", e todos caem na gargalhada, e logo complementa: "é despacho, sai fora". A fala do personagem Didi faz intertextos/alusões a cultos africanos, provavelmente, pelo fato de ser um personagem afrodescendente que está esticado ao chão. O exercício da alusão está presente em diversos esquetes do grupo e serve para evocar outros contextos com o sentido de provocar o riso. Samoyault (2008) esclarece que a alusão sempre remete a um texto anterior, sem indicar a heterogeneidade como na prática da citação. A autora ainda explica que:

\footnotetext{
Não plenamente visível, ela pode permitir uma conivência entre o autor e o leitor que chega a identificá-la. A alusão depende mais do efeito de leitura que as outras práticas intertextuais: tanto pode não ser lida como pode também o ser onde não existe. A percepção da alusão é freqüentemente [sic] subjetiva e seu desvendamento raramente necessário para a compreensão do texto. (SAMOYAULT, 2008, p. 51).
}

Didi cheira o caqui e fala: "Ih, príncipe, grotóco no caqui [...], comeu aqui caiu ali". No momento, Zacarias comenta que irão precisar de um príncipe para beijar Branca de Neve para despertá-la, porém nenhum dos dois quer fazer isso. Didi ainda menciona: "eu não vou beijar esse brijelão aí, [risos] eu prefiro beijar a bruxa". Zacarias diz: "Mas não pode fazer isso, não, pois assim vai mudar o curso da história”, e Didi rebate: "então joga no rio Guandu", uma referência ao importante rio do estado do Rio de Janeiro. Neste sentido percebe-se a evocação ao hipotexto Branca de Neve, há uma preocupação com o curso da história original para manter a coerência com a origem textual, mas já com transformações. "Parece que estou ouvindo um cantar de um príncipe", fala Zacarias. E os dois personagens 
falam juntos: "É um príncipe audaz, forte e corajoso". Em instantes, aparece Dedé vestido de príncipe com trajes cor-de-rosa. Ele canta trechos da canção Sonhando assim, do clássico de 1937, de Walt Disney, e que era proferida por Branca de Neve: “Esta canção que eu canto, fala só de você...” (ver figuras 5 e 6 ).

Em seguida os três personagens começam a cantar e a dançar juntos uma canção brasileira, Abre a roda (compositores: Sarajane, Robson de Jesus, Alfredo Moura), inserida no texto como uma espécie de colagem de um texto em outro: "Abre a rodinha meu amor, abre a rodinha", cantam os três. O cenário corroborava o que Samoyault (2008) aponta sobre a recuperação de materiais para a produção textual, em que elementos são tomados como empréstimos de outros contextos, numa forma de transpor referências e que, as vezes, também pode ser um elemento externo à ficção.

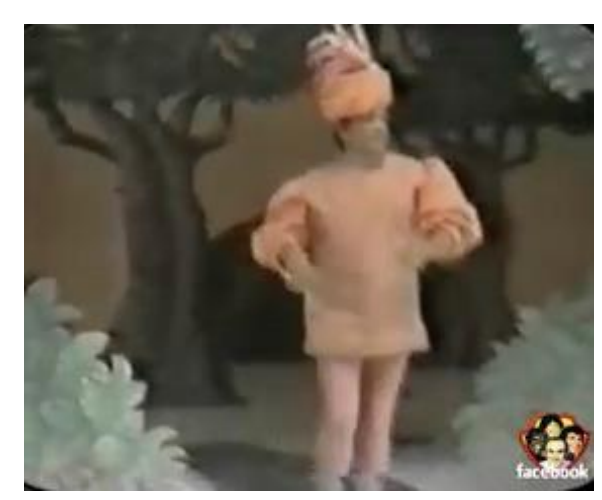

Figura 5: still frame do esquete O grotóco do caqui (1988). Fonte: recorte do autor.

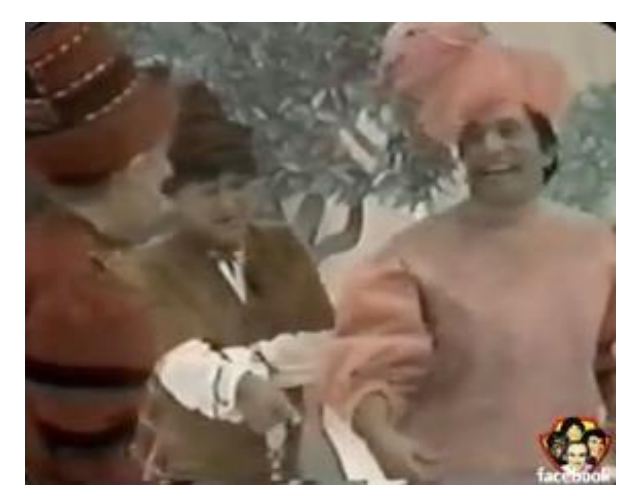

Figura 6: still frame do esquete O grotóco do caqui (1988). Fonte: recorte do autor.

Didi, a todo momento, trata Dedé sempre no sentido de duvidar de sua sexualidade: "princesa cor-de-rosa", "minha senhora", "príncipa", "madame”, “donzela". Zacarias e Didi explicam que para a princesa acordar, ela precisa ser beijada por um "príncipe audaz, forte $e$ corajoso", novamente, um reforço dos arquétipos dos contos de fada. Dedé responde que iria resolver o problema e Didi fala: "cuidado com o bafo de azinhavre, seja o que Deus quiser". Novamente as características do Mussum são enunciadas. Pouco antes de beijar Mussum, Didi dirige metatextualmente a frase a Dedé: "Peraí, quando a Globo te paga por mês pra dar um beijo?". Todos os demais personagens e o público começam a rir. Dedé responde: "Isso não tava no contrato quando eu comecei”. Essa situação contribui como uma ferramenta importante para a provocação do riso nos esquetes de Os Trapalhões. A prática da metatextualidade é uma relação crítica, dentre um texto e outro, e que pode aparecer de forma 
alusiva ou silenciosa. Geralmente é percebida, a partir do repertório do leitor/espectador e está relacionada às complementações do texto, e constrói relações entre textos que estão tangenciados à sua concepção estrutural. É um exercício de metalinguagem em que há a possibilidade de promover uma reflexão ou autorreflexão textual.

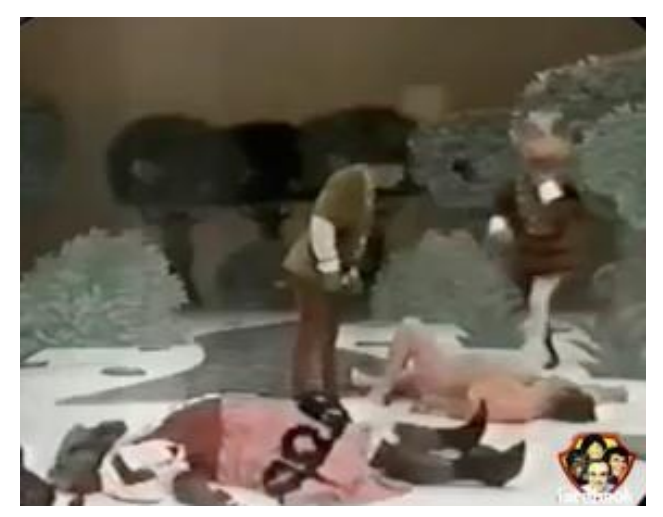

Figura 7: still frame do esquete $O$ grotóco do caqui (1988).

Fonte: recorte do autor.

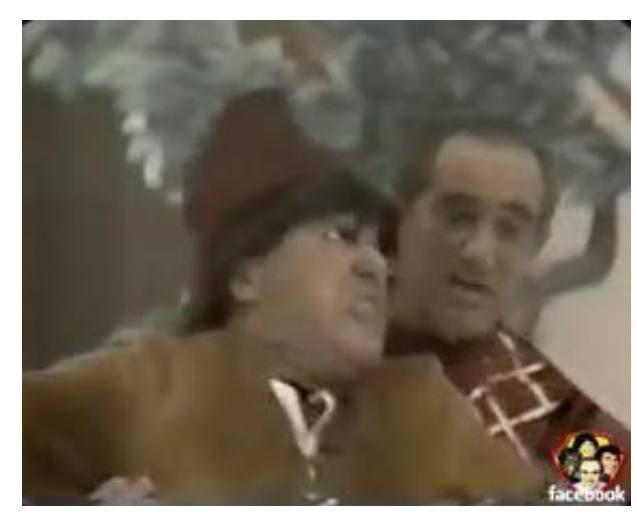

Figura 8: still frame do esquete $O$ grotóco do caqui (1988).

Fonte: recorte do autor.

Dedé começa a se esquivar de beijar Mussum, até que Didi faz o ato acontecer forçadamente. Dedé cai ao chão e Didi diz que ele "morreu com o bafo do miocárdio" e todos começam a rir (ver figura 7). Preocupado, Zacarias fala que um dos dois precisa beijar Mussum, e Didi deixa claro que não vai beijar a "morcegona", um dos jargões utilizados pelo seu personagem nos programas de Os Trapalhões. Zacarias beija então Mussum, e começa a passar mal. Pouco antes de cair ao chão, dança e canta, novamente, a música Abre a roda (ver figura 8). Em seguida, aparece outro príncipe, interpretado pelo cantor Fagner. Didi ainda olhando para Mussum fala: "isso se chama Bafo Mortífero, aquele filme", numa alusão ao filme Máquina mortífera (1987, Richard Donner), um recente sucesso dos cinemas, próximo da época em que foi gravado o esquete. Fagner pede explicações do que aconteceu, e Didi esclarece que a lenda conta que uma princesa tomou "grotóco no caqui" ao invés de ter sido uma maçã e que agora um príncipe precisaria acordá-la com um beijo (ver figuras 9 e 10). 


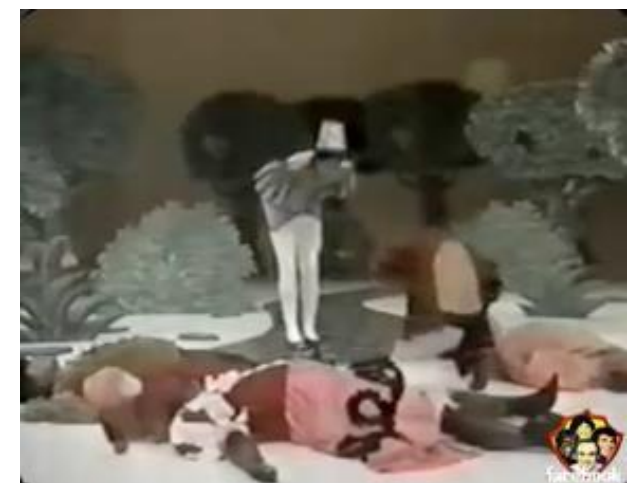

Figura 9: still frame do esquete O grotóco do caqui (1988). Fonte: recorte do autor.

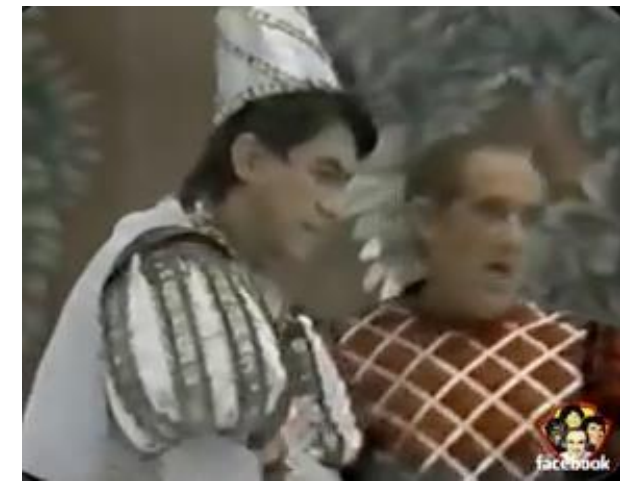

Figura 10: still frame do esquete O grotóco do caqui (1988). Fonte: recorte do autor.

Fagner diz: "há anos estou de olho nessa princesinha Mussunga" e Didi fala que não sabia o nome dela. Fagner responde que seu nome era "Mussumguinha", numa alusão arquitextualmente ao nome do personagem que interpretava a princesa. Ele a beija e, em seguida, também cai ao chão. Didi começa a rir e fala: "Eu não sei como termina isso", e se encerra o esquete.

Tem-se aqui, não somente a evocação hipotextual da obra de origem, mas também das diversas alusões que são feitas a outras obras e a alusão arquitextual aos nomes de origem dos personagens, como no caso, "Mussunga" que está relacionado ao nome do personagem Mussum. A relação arquitextual é uma das formas mais abstratas e implícitas do texto e, conforme Genette (2010, p. 17), é "uma relação completamente silenciosa, que, no máximo, articula apenas uma menção paratextual [...] de caráter puramente taxonômico". O intertexto arquitextual está sempre ligado aos títulos e aos subtítulos que deixam as suas marcas em relação ao gênero da obra, discurso e enunciados.

Essas sempre foram práticas corriqueiras dos textos de Os Trapalhões, numa utilização constante de recursos intertextuais.

\section{Considerações finais}

De um modo geral, os hipertextos televisivos de Os Trapalhões colaboram para uma relação textual, figurada como um palimpsesto, assim como teoriza Genette. Não somente a obra $O$ grotóco do caqui, de Os Trapalhões, mas também a maioria dos esquetes do grupo, se configuram num trânsito textual e corroboram com o exposto por Genette: 
A arte de "fazer o novo com o velho" tem a vantagem de produzir objetos mais complexos e mais saborosos do que os produtos "fabricados": uma função nova se superpõe e se mistura com uma estrutura antiga, e a dissonância entre esses dois elementos co-presentes dá sabor ao conjunto". (GENETTE, 2010, p. 144).

Samoyault (2008, p. 139) constata também que esses trabalhos intertextuais causam uma espécie de efeito palimpsesto, "ou seja, o efeito de difração, na obra, de um brilho particular emanando do intertexto e que prolonga um no outro".

A hipertextualidade se configura numa espécie de circulação de textos dentro de um jogo que, segundo Genette (2010, p. 145), “nenhuma forma de hipertextualidade ocorre sem uma parte de jogo, inerente à prática da reutilização de estruturas existentes", algo que é possível remeter às diferentes formas de produções textuais, oriundas de Os Trapalhões, quando se utilizam de hipotextos, ao jogar com eles e, ao mesmo tempo, se jogar dentro deles.

A circulação de textos provocada pela hipertextualidade "tem em si mesma o mérito específico de relançar constantemente as obras antigas em um novo circuito de sentido" (GENETTE, 2010, p. 146). Os Trapalhões, neste caminho, reciclavam obras das mais diversas e mantinham seus espectadores num constante contato de entrelaçamento intertextual. Este cenário também se apresentava nos filmes cinematográficos e nas histórias em quadrinhos do grupo, o que configurava uma espécie de jogo hipertextual.

\section{Referências}

ARISTÓTELES. Poética. [tradução Eudoro de Souza]. São Paulo: Ars Poetica, 1993.

BAKHTIN, Mikhail. A cultura popular na Idade Média e no Renascimento: o contexto de François Rabelais. $7^{\text {a }}$ ed. São Paulo: Hucitec, 2010.

BARTHES, Roland. Introdução à análise estrutural da narrativa. In.: BARTHES, Roland; GREIMAS, A. J.; BREMOND, Claude; ECO, Umberto; GRITTI, Jules; MORIN, Violette; METZ, Christian; TODOROV, Tzvetan; GENETTE, Gérad. (Orgs.). Análise estrutural da narrativa: pesquisas semiológicas. $4^{\mathrm{a}}$ ed. Petrópolis, RJ: Editora Vozes Limitada, 1976. p. 19-60.

COMPARATO, Doc. Da criação ao roteiro: teoria e prática. São Paulo: Summus, 2009.

ECO, Umberto. Sobre a literatura. Rio de Janeiro: BestBolso, 2011.

GENETTE, Gérard. Palimpsestos: a literatura de segunda mão. Belo Horizonte: Edições Viva Voz, 2010. 
MACHADO, Arlindo; VÉLEZ, Marta Lucía. Questões metodológicas relacionadas com a análise de televisão. E-Compós (Brasília), v. 8, 2007, p. 1-15.

SAMOYAULT, Tiphaine. A intertextualidade. São Paulo: Hucitec, 2008.

STAM, Robert. Introdução à teoria do cinema. Campinas: Papirus, 2003. 